Pharmaceutical Co., Ltd., SymBio Pharmaceuticals Ltd., Janssen Pharmaceutical K.K., Celltrion Inc., Nipponkayaku Co. Ltd., and UCB Japan, Consultant for: Astra Zeneca K.K., Eli Lilly Japan K.K., Novartis Pharma K.K., Mitsubishi Tanabe Pharma Co., Abbivie GK, Nipponkayaku Co.Ltd, Janssen Pharmaceutical K.K., Astellas Pharma Inc., Taiho Pharmaceutical Co. Ltd., Chugai Pharmaceutical Co. Ltd., Taisho Toyama Pharmaceutical Co. Ltd., GlaxoSmithKline K.K., UCB Japan Co. Ltd., Consultant for: AbbVie, Asahi Kasei, Astellas, AstraZeneca, AYUMI, Bristol-Myers Squibb, Chugai, Daiichi Sankyo, Eisai, Eli Lilly Japan, Janssen, Mitsubishi Tanabe, Nippon Kayaku, Novartis, Pfizer Japan Inc, Taiho, Taisho Toyama, Takeda, Teijin, Consultant for: Astra Zeneca K.K., Eli Lilly Japan K.K., Novartis Pharma K.K., Mitsubishi Tanabe Pharma Co., Asahi Kasei Medical K.K., AbbVie GK, Daiichi Sankyo Co., Ltd., Bristol Myers Squibb, and Nipponkayaku Co. Ltd., Speakers bureau: Astellas Pharma Inc., Bristol Myers Squibb, Chugai Pharmaceutical Co., Ltd., Mitsubishi Tanabe Pharma Co., Pfizer Japan Inc., Santen Pharmaceutical Co., Ltd., Takeda Pharmaceutical Co., Ltd., Teijin Pharma Ltd., AbbVie GK, Asahi Kasei Pharma Corp., Taisho Toyama Pharmaceutical Co., Ltd., SymBio Pharmaceuticals Ltd., Janssen Pharmaceutical K.K., Celltrion Inc., Nipponkayaku Co. Ltd., and UCB Japan, Speakers bureau: AbbVie, Asahi Kasei, Astellas, AstraZeneca, AYUMI, Bristol-Myers Squibb, Chugai, Daiichi Sankyo, Eisai, Eli Lilly Japan, Janssen, Mitsubishi Tanabe, Nippon Kayaku, Novartis, Pfizer Japan Inc, Taiho, Taisho Toyama, Takeda, Teijin, Speakers bureau: AbbVie GK., Bristol-Myers K.K., Chugai Pharmaceutical Co. Ltd., Mitsubishi Tanabe Pharma Co., Pfizer Japan Inc., Astellas Pharma Inc, Diaichi Sankyo Co. Ltd., Eisai Co. Ltd., Sanofi K.K., Teijin Pharma Ltd., Takeda Pharmaceutical Co. Ltd., Novartis Pharma K.K., Keisuke Izumi Grant/research support from: Asahi Kasei Pharma, Speakers bureau: Asahi Kasei Pharma Corp, Astellas Pharma Inc., Bristol Myers Squibb, Chugai Pharmaceutical Co., Ltd., Eli Lilly Japan K.K., Mitsubishi Tanabe Pharma Co., Mitsuhiro Iwahashi: None declared, Hitoshi Fujimiya: None declared

DOI: 10.1136/annrheumdis-2019-eular.5358

\section{SAT0119 CREATE RISK PREDICTION MODELING AND DRUG WITHDRAW ROAD MAP THROUGH PATTERN EXTRACTION AND DATA MINING: A MASTER ALGORITHM DEVELOPMENT FROM THE SMART SYSTEM OF DISEASE MANAGEMENT (SSDM)}

Yan Zhao ${ }^{1}$, LI Xiaomei ${ }^{2}$, Rong $\mathrm{Mu}^{3}$, Hua Wei ${ }^{4}$, Lingli Dong ${ }^{5}$, Xiaoxia Zuo ${ }^{6}$, LI Shouxin ${ }^{5}$, Hongsheng Sun ${ }^{7}$, Guanmin Gao ${ }^{8}$, Lijun Wu ${ }^{9}$, Hui Xiao ${ }^{10}$, Yuhua Jia ${ }^{10}$, Fei $X_{i a{ }^{10}}{ }^{10}$, SSDM Collaboration Group, China. ${ }^{1}$ Peking Union Medical College hospital, Beijing, China; ${ }^{2}$ the First Affiliated Hospital of University of Science and Technology of China, Hefei, China; ${ }^{3}$ People's Hospital, Beijing University Medical School, Beijing, China; ${ }^{4}$ Northern Jiangsu People's Hospital, Yangzhou, China; ${ }^{5}$ Tongji Hospital, Tongji Medical Colllege, Huazhong University of Science and Technology, Wuhan, China; ${ }^{6}$ Xiangya Hospital Centeral South University, Changsha, China; ${ }^{7}$ Shandong Provincial Hospital Affiliated to Shandong University, Jinan, China; ${ }^{8}$ the First Affiliated Hospital of Zhengzhou University, Zhengzhou, China: ${ }^{9}$ People's Hospital of Xinjiang Uygur Autonomous region, Urumchi, China; ${ }^{10}$ Shanghai Gothic Internet Technology Co., Ltd., Shanghai, China

Background: Combination therapy with DMARDs for treating RA is standard of care. However, certain rates of adverse events (AEs) are unavoidable. The stigmas are how to predict the risk and how to define drug withdraw sequence if $\mathrm{AEs}$ persist for optimal risk reductions. The decisions made are always empirically.

Objectives: To develop a risk prediction model and an algorithm for drug withdraw sequence based on data mining from the SSDM.

Methods: SSDM is an interactive mobile disease management tool, including two application systems (APPs) for both the doctors and the patients. The patients can input medical records (including medication and laboratory test results) and perform self-evaluation (DAS28, HAQ) via App. The data synchronizes to mobiles of authorized rheumatologists through cloud and advices could be delivered. In previous studies, we demonstrated that patients could master SSDM after training.

In order to develop a prediction model and the master algorithm, abnormal white blood cell counts (WBC) and alanine aminotransferase (ALT) elevation were targeted. Data was collected, extracted, validated, and Bayesian networking, data mining, modeling were performed. WBC under $4 \mathrm{k} / \mathrm{ml}$ is defined as leukocytopenia (LP), over $10 \mathrm{k} / \mathrm{ml}$ as infection predisposing (IP), and ALT > $40 \mathrm{U} / \mathrm{L}$ as ALT elevation.
Results: From Jun 2014 to Jan 2019, 44,533 RA patients from 587 centers registered in SSDM. 135 different drugs and 882 combination therapies are identified. LP happens at 317 and IP at 286, ALT at 322 cases in 641 treatment regiments. Among them, MTX based regiments are 257 types, and the risk ratio $(R R)$ are profiled as prediction model by com paring each $A E$ rate of combination regiment with that of MTX monotherapy (Fig 1). The RR ranges from 0.28 to 6.28 . The highest risk combination of prednisone (Pred), leflunomide (LEF), methotrexate (MTX) hydroxychloroquine (HCQ) and Celecoxib is selected (RR=6.28) to develop a master algorithm. Figure 2 shows Bayesian network, in which, quartet correlaties with 31 different regiments. Based on Bayesian method, the probabilities of LP, IP and ALT are plotted through 64 modeling, and the algorithm for drug withdraws strategies is generated. Drug withdrawing sequence for LP is $\mathrm{HCQ}$, then Cel, then LEF, then Pre, the risks of LP are reduced by $41 \%, 22 \% 36 \%$ and $15 \%$, respectively. For IP, withdraw sequence is Pred, then LEF, then Cel, then HCQ, the risks of IP are reduced by $45 \%, 28 \%, 23 \%$ and $4 \%$, respectively, For ALT, withdraw sequence is MTX, then Pred, LEF, then Cel, the risks of ALT are reduced by $48 \%, 8 \%, 7 \%$ and $6 \%$.

Conclusion: Through patterns extraction, data mining, modeling, and Bayesian networking, a risk prediction model and a master algorithm for drug withdraw strategy in reduction of AEs are developed, which are expendable and replicatablei. Via continuing data inputs and machine leaning, an artificial intelligent system in assisting clinical forecast and decision-making may be achieved with SSDM.

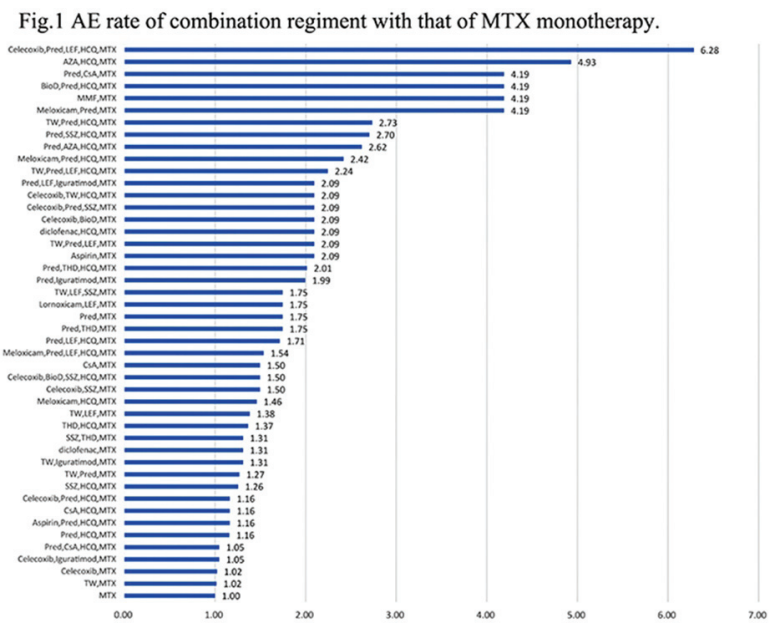

Figure 1

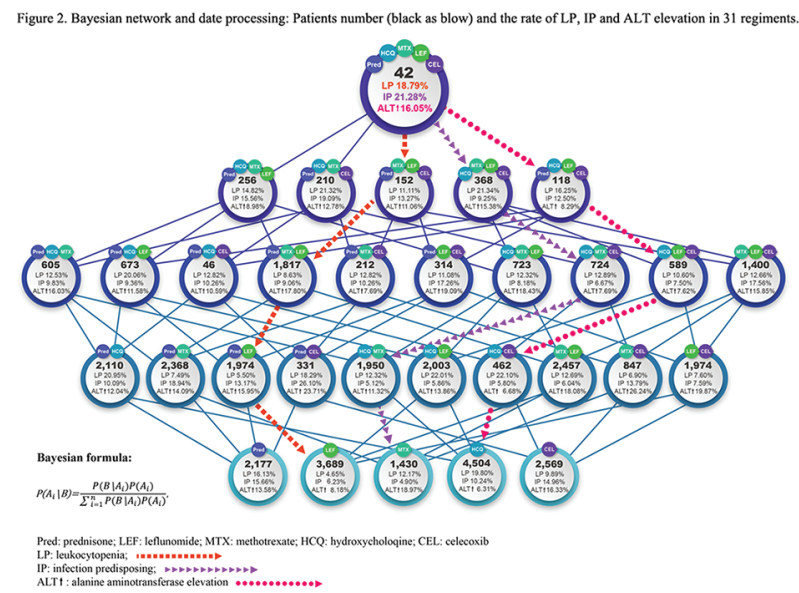

Figure 2

Disclosure of Interests: None declared DOI: 10.1136/annrheumdis-2019-eular.5292 


\section{Rheumatoid arthritis - biological DMARDs}

\section{SAT0120 COMPARATIVE EFFECTIVENESS OF TOFACITINIB AND TNF INHIBITORS SINCE 2014. IMPACT OF COMBINATION WITH METHOTREXATE}

Denis Choquette $^{1}$, Louis Bessette ${ }^{2}$, Loïc Choquette Sauvageau ${ }^{1}$, Isabelle Ferdinand ${ }^{1}$, Paul Haraouil ${ }^{1}$, Frédéric Massicotte ${ }^{1}$, Jean-Pierre Pelletier ${ }^{1}$, Jean-Pierre Raynauld ${ }^{1}$, Marie-Anaïs Rémillard ${ }^{1}$, Diane Sauvageau ${ }^{1}$, Édith Villeneuve', Louis Coupal'. ${ }^{1}$ Institut de Recherche en Rhumatologie de Montréal (IRRM), Rhumatology, Montréal, Canada; ${ }^{2}$ Centre de l'Ostéoporose et de Rhumatologie de Québec (CORQ), Québec, Canada

Background: Tofacitinib (TOFA), a targeted synthetic DMARD, has been approved for the treatment of rheumatoid arthritis (RA) in Canada since April 2014. This oral agent preferentially inhibits signalling by cytokine receptors associated with JAK1 and JAK3 subunits. It is also indicated for the treatment of PsA and UC since October 2018. Clinical experience with this molecule has been increasing, and questions relating to its efficacy and long-term safety are of interest. Data collection through RHUMADATA $^{\circledR}$, a Quebec based clinical database and registry, allows comparison of newer options with more traditional agents such as tumor necrosis factor inhibitors (TNFi).

Objectives: The current analysis compares TOFA to TNFi used with and without methotrexate (MTX) among patients with RA.

Methods: Data collected since January 1, 2014 (when TOFA became available in Canada) at the Institut de Recherche en Rhumatologie de Montréal (IRRM) and the Centre de l'Ostéoporose et de Rhumatologie de Québec (CORQ) was extracted from Rhumadata ${ }^{\circledR}$ on January 7, 2019. Patients initiated on TOFA or a TNFi (adalimumab, certolizumab, etanercept, golimumab, infliximab) without or with MTX were selected. Data include baseline characteristics (socio-demographic variables, concomitant and past medication, comorbidities and the Charlson comorbidity index $(\mathrm{CCI})$ ), variables measured over time (lab results, patient and physicianreported outcomes, and disease activity measures) and persistence data (treatment duration, reason for cessation). The groups were compared to identify potential confounder, and persistence data were analyzed using Kaplan-Meier and Cox methods.

Results: A total of 480 patients were prescribed TOFA ( $n=162)$ or a TNFi $(n=318)$ since January 1,2014 . Of those, $57 \%(n=92)$ and $70 \%(n=224)$ were treated with MTX in the TOFA and TNFi group respectively and mean disease duration was 12.1 (standard deviation=11.0) and 7.2 (8.1) years. TOFA and TNFi represent the first treatment following CsDMARD-IR for $33 \%$ (TOFA) and $62 \%$ (TNFi). In the TOFA group, $84 \%$ were women, $15 \%$ were smokers and the mean age at treatment initiation was 57.7 (11.5) years. In the TNFi group, $77 \%$ were women, $12 \%$ were smokers and the mean age at treatment initiation was 54.2 (13.7) years. At treatment initiation, patient global, pain and fatigue assessments, made on a visual analogue scale ranging from 1 to 10 , were $5.6(2.5), 5.9(2.7)$ and 5.7 (2.9) in the TOFA group and 5.0 (2.9), 5.5 (3.0) and 5.1 (3.1) in the TNFi group. Baseline disease activity was assessed as moderate or high/ severe in $85.9 \%$ and $76.7 \%$ of TOFA (?) patients (DAS28(4)-ESR criteria). Among the $56(35 \%)$ TOFA and $146(46 \%)$ TNFi patients ceasing therapy, reasons for cessation were "inefficacy" (TOFA: $64 \%$ vs TNFi: $56 \%$ ) and "adverse events" (TOFA: 16\% vs TNFi: $11 \%$ ). Patients remaining on TOFA and TNFi therapy at last follow-up had an average treatment duration of 1.7 (1.1) and 2.7 (1.5) years and no difference in retention was observed between TOFA and TNFi treated patients (log-rank $\mathrm{p}=0.41$ ). Patients treated with a TNFi in combination with MTX had better treatment retention than those treated without MTX (log-rank $p=0.04$ ) while patients treated with TOFA+/-MTX had similar retention (log-rank $p=0.96$ ). These results remain unchanged when adjusted for gender, age at treatment initiation, disease duration, and comorbidities.

Conclusion: In our real-world data registry, treatment with TNFi and TOFA yielded similar retention over time. Subjects treated with TNFi and MTX remained on treatment longer than those treated without MTX while subjects treated with tofacitinib with or without MTX had similar retention. Disclosure of Interests: Denis Choquette Grant/research support from: Abbvie, Amgen, Eli Lilly, Novartis, Pfizer, Sandoz, Consultant for: Abbvie, Amgen, Eli Lilly, Novartis, Pfizer, Sandoz, Speakers bureau: Abbvie, Amgen, Eli Lilly, Novartis, Pfizer, Sandoz, Louis Bessette Grant/research support from: AbbVie, Amgen, Bristol-Myers Squibb, Celgene, Eli Lilly, Janssen, Novartis, Pfizer Inc, Roche, Sanofi, UCB, Consultant for: AbbVie, Celgene, Eli Lilly, Novartis, Pfizer Inc, Loïc Choquette Sauvageau: None declared, Isabelle Ferdinand Consultant for: AbbVie, Amgen, Novartis, Pfizer, Speakers bureau: Amgen, Pfizer, Paul Haraoui Grant/research support from: Abbvie, Amgen, Pfizer, UCB, Consultant for: Abbvie, Amgen, Lilly, Pfizer, Sandoz, UCB, Speakers bureau: Pfizer, Frédéric
Massicotte Consultant for: AbbVie, Pfizer, Janssen, Eli Lilly, Speakers bureau: Janssen, Jean-Pierre Pelletier Shareholder of: Shareholder in ArthroLab Inc., Grant/research support from: Study funded by TRB Chemedica SA, Consultant for: TRB Chemedica SA, Jean-Pierre Raynauld Consultant for: ArthroLab Inc., Marie-Anaïs Rémillard Consultant for: Abbvie, Amgen, Eli Lilly, Novartis, Pfizer, Sandoz, Paid instructor for: Abbvie, Amgen, Eli Lilly, Novartis, Pfizer, Sandoz, Speakers bureau: Abbvie, Amgen, Eli Lilly, Novartis, Pfizer, Sandoz, Diane Sauvageau: None declared, Édith Villeneuve Consultant for: AbbVie, UCB, Celgene, Roche, Pfizer, Amgen, BMS, Sanofi-Genzyme, Paid instructor for: AbbVie, Speakers bureau: AbbVie, Pfizer, BMS, Roche, Louis Coupal: None declared DOI: 10.1136/annrheumdis-2019-eular.3110

\section{SAT0121 EFFECT OF SARILUMAB ON GLYCOSYLATED HEMOGLOBIN IN PATIENTS WITH RHEUMATOID ARTHRITIS AND DIABETES}

Mark C. Genovese ${ }^{1}$, Gerd Rüdiger Burmester ${ }^{2}$, Owen Hagino ${ }^{3}$, Hubert van Hoogstraten ${ }^{3}$, Erin Mangan ${ }^{4}$, Karthinathan Thangavelu ${ }^{5}$, Roy Fleischmann ${ }^{6}$, Thomas Mandrup-Poulsen ${ }^{7} .^{1}$ Stanford University Medical Center, Palo Alto, CA, United States of America; ${ }^{2}$ Charité University Medicine, Berlin, Germany; ${ }^{3}$ Sanofi Genzyme, Bridgewater, NJ, United States of America; ${ }^{4}$ Regeneron Pharmaceuticals, Inc., Tarrytown, NY, United States of America; ${ }^{5}$ Sanofi Genzyme, Boston, MA, United States of America; ${ }^{6}$ Metroplex Clinical Research Centre, Dallas, TX, United States of America; ${ }^{7}$ University of Copenhagan, Copenhagen, Denmark

Background: Sarilumab is a human mAb blocking the IL-6R $\alpha$, approved for adult patients with moderately to severely active RA. The incidence of Type 2 diabetes is increased in patients with RA, and elevated IL-6 may be an independent risk factor.

Objectives: We conducted a post hoc analysis into the effect of sarilumab treatment on glycosylated hemoglobin (HbA1c) levels.

Methods: TARGET (NCT01709578) was a 24-week study of sarilumab $150 / 200 \mathrm{mg}$ q2w vs placebo (all +csDMARD) in TNFi-inadequate response/intolerant (IR/INT) patients. MONARCH (NCT02332590) was a 24-week monotherapy study of sarilumab $200 \mathrm{mg}$ q2w vs adalimumab 40 mg q2w in MTX-IR/INT, bDMARD-naïve patients. There were 78/546 $(14.3 \%)$ and $28 / 369(7.6 \%)$ diabetic patients per ADA criteria (baseline fasting glucose $\geq 7 \mathrm{mmol} / \mathrm{L}$ or baseline $\mathrm{HbA} 1 \mathrm{c} \geq 6.5 \%$ ) in TARGET and MONARCH, respectively.

Results: In patients with RA and diabetes, the decrease in $\mathrm{HbA1c}$ at Week 24 was greater in sarilumab-treated groups than placebo (TARGET; in combination with csDMARDs) or adalimumab (MONARCH; monotherapy) groups (Figure). There was no interaction between change in $\mathrm{HbA1c}$ and corticosteroid use nor were changes in $\mathrm{HbA} 1 \mathrm{c}$ correlated with changes in CRP, DAS28-CRP, or hemoglobin level. Among sarilumabtreated patients, those with baseline $\mathrm{IL}-6>37.5 \mathrm{pg} / \mathrm{mL}$ ( $>3 \times$ upper limit of normal) had greater reductions in HbA1c (least squares mean change 0.27 ) than those with baseline IL-6 levels $\leq 37.5 \mathrm{pg} / \mathrm{mL}$ (least squares mean change -0.11). Sarilumab safety profile was similar in diabetic vs non-diabetic patients with RA.

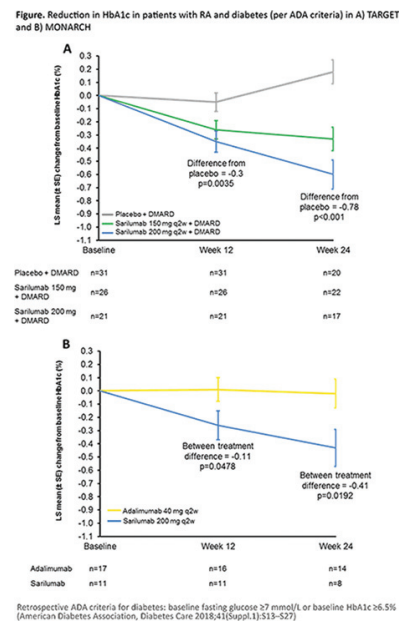

Conclusion: Patients with RA and diabetes treated with sarilumab had greater improvements in $\mathrm{HbA} 1 \mathrm{c}$ than those treated with adalimumab or placebo. With monotherapy, differences between sarilumab and 